\title{
Social class and gender impacting change in bilingual settings: Spanish subject pronoun use in New York
}

\author{
N A O M L A P I D U S H I N \\ Department of Spanish \& Portuguese, Department of Linguistics \\ The University of New Mexico \\ MSC03-2100, 1 University of New Mexico \\ Albuquerque, NM 87131-0001, USA \\ naomishin@unm.edu \\ R I C A R D O O T H E G U Y \\ Linguistics Program \\ Graduate Center, City University of New York \\ 365 Fifth Avenue, New York, NY 10016, USA \\ rotheguy@gc.cuny.edu
}

\section{A B S T R A C T}

This study examines the role of social class and gender in an ongoing change in Spanish spoken in New York City (NYC). The change, which has to do with increasing use of Spanish subject pronouns, is correlated with increased exposure to life in NYC and to English. Our investigation of six different national-origin groups shows a connection between affluence and change: the most affluent Latino groups undergo the most increase in pronoun use, while the least affluent undergo no change. This pattern is explained as further indication that resistance to linguistic change is more pronounced in poorer communities as a result of denser social networks. In addition we find a women effect: immigrant women lead men in the increasing use of pronouns. We argue that the women effect in bilingual settings warrants a reevaluation of existing explanations of women as leaders of linguistic change. (Language change, social class, gender, bilingualism, Spanish in the US, pronouns)*

\section{N T R O D U C T I O N}

In monolingual settings, gender and social class have been shown to be relevant variables in our understanding of language change. But are these variables also relevant to language change in bilingual settings and, more specifically, in immigrant bilingual settings? In this article we examine an ongoing change in the Spanish spoken in New York City (NYC), and find evidence that this change occurs most rapidly among the more affluent Latino communities and among women. 
The change in progress in Spanish in NYC studied in this article has to do with differences in the variable use of subject personal pronouns in Spanish (e.g. canto yo canto 'I sing,' cantas $\sim$ tú cantas 'you sing,' etc.). Most corpora gathered in the Spanish-speaking world show tokens of finite verbs appearing with a subject pronoun in twenty to forty percent of all occurrences. We refer to this measure as the PRONOUN RATE. The low pronoun rates in Spanish directly contrast with rates in English, in which the presence of subject pronouns with finite verbs reaches nearly categorical levels in many discourse types. This difference of pronoun rate between Spanish and English makes this feature ideal for studies investigating contact-induced change in bilingual settings and the variables that impact it. ${ }^{1}$ As Latinos spend more time in NYC and become more bilingual, their Spanish pronoun rates tend to increase (Livert \& Otheguy 2010), and this increase becomes even more evident in the course of one apparent-time generation, ${ }^{2}$ as bilingualism tends to become the community norm (Otheguy, Zentella, \& Livert 2007; Otheguy \& Zentella 2012).

These rising pronoun rates appear to be due to the influence of English, as well as to dialect leveling. The majority of Latinos in New York hails from the Spanishspeaking Caribbean, where pronoun rates are higher than in the Latin American Mainland. In NYC, both Caribbeans and Mainlanders experience pronoun rate increases, but the increase is somewhat greater among Mainlanders (Otheguy \& Zentella 2012:99-102,117-22,135-45). This difference between Mainlanders and Caribbeans suggests that exposure to two high-pronoun types of speech (English and Caribbean Spanish) creates a kind of double-barrel effect, resulting in greater increase in pronoun use among Mainlanders.

But even though, for New York, the fact of change and the partial attribution of its causes to contact with English are now well established, the question remains of pinpointing the exact demographic location of the change. In the studies mentioned above, inferences regarding language contact are made about the Latino population of New York City as a whole on the basis of such variables as immigrant generation and years spent in the City. But this approach, while useful in making the point about overall change and its likely causes, leaves unattended important questions regarding differences between subgroups of the City's Latino population.

The data for our research come from the Otheguy-Zentella corpus, a large, stratified collection of oral interviews with Latino New Yorkers, described in detail in Otheguy \& Zentella (2012). As in previous work on the corpus, we conduct here multivariate analyses of pronoun rates that look at the extent of the speakers' exposure to NYC life. But in a more finely grained treatment, we separate participants by national origin, that is, whether they or their parents trace their origins to Colombia, Cuba, Dominican Republic, Ecuador, Mexico, or Puerto Rico. This approach uncovers patterns that were not studied in the earlier works, and in doing so opens a brand new avenue to explanation. Our explanations take into account both internal and external factors. 
With regard to internal factors, we entertain the possibility that patterns of pronominal usage in Spanish in NYC may be responding, in part, to the operation of a CEILING EFFECT. As we lay out in more detail in the Discussion section, we note that the least change in pronoun rates is found among speakers from the national-origin group that comes into the City with the highest pronoun rates, namely the Dominicans. We tentatively suggest that, past a certain occurrence rate, the reference-tracking mechanism embodied in Spanish subject pronoun usage is likely to become inoperative.

With regard to the external factors that lead to the explanatory path for the patterns documented here, our new analyses reveal a clearly ascertainable distinct profile for the leaders of the change investigated in this article. As we already knew from Otheguy \& Zentella (2012), the leaders of the change in the use of pronouns are predominantly Latinos who: (a) have had the most exposure to life in NYC and (b) have higher levels of English proficiency. But as we show here, they are also predominantly Latinos who: (c) belong to more affluent nationalorigin communities, and (d) are women. Our understanding of the role of affluence comes from analyses showing that rates of increase in pronoun use are different for different national-origin groups, revealing a hierarchy of change. Whereas Dominicans change the least, Colombians and Cubans change the most. Income and socioeconomic data from the Pew Hispanic Center, as well as the Community Service Society of New York, show that the hierarchy of change in pronoun rates in NYC mirrors a hierarchy of affluence. Colombians and Cubans are the two most affluent Latino groups in NYC, while Dominicans are among the poorest. Thus we show a pattern that is opposite to the trend in monolingual settings where the leaders of change tend to be working class or lower middle class (Labov 2001:31-32; 2006:380-403). The pattern we have turned up also conflicts with the prevailing popular view in the NYC Latino communities as well as among many Latin American and Peninsular visitors to the City, a view that associates Anglicized usage with the speech of the poor. In our results, persistence of ancestral Latin American usage patterns in Spanish in New York is strongly associated with lower socioeconomic status, while the more Anglicized usage is connected to the more affluent. Why should this be the case? One explanation can be found in the well-documented association between lower socioeconomic status and the denser social networks that tend to correlate with more conservative patterns of language use (Milroy 1987; Milroy \& Milroy 1992). In other words, the Latino national groups who are on average more affluent are likely to also have looser social networks and be therefore more susceptible to external influence and change.

In addition to revealing an inverse relationship between affluence and contactinduced change in bilingual New York, we find that the ongoing change is led by first-generation women. While it is well established that women are typically at the vanguard of change in monolingual settings (Labov 2001; Eckert \& McConnell-Ginet 2003; Cheshire 2004), the current study makes an important contribution 
to the sociolinguistic literature by showing that this generalization can be extended to changes in minority languages in contact with majority languages. To explain this WOMEN EFFECT, we look to social networks as the pathway for the spread of language change. We propose that the position of linguistic leadership occupied by women is the result of their extensive contact with high-pronoun using second-generation Latinos, including their own children. Furthermore, we suggest that current explanations for the women effect in monolingual settings (Labov 2001; Eckert \& McConnell-Ginet 2003) need to be modified to incorporate our new findings.

PREVIOUS RESEARCH ON THE IMPACT OF

GENDER A N C L A S ON LANGUAGE CHANGE

The abundant research on monolingual settings has shown a strong tendency for language change to be led by working or lower middle class people and by women (Eckert 1989; Labov 2001:366, 2006:380-403; Eckert \& McConnellGinet 2003). But for bilingual settings, the leaders of change are likely to be the same as those reported in the vast literature on LANGUAGE SHIFT, namely the people who are most proficient in the majority out-group language and who have the least contact with other speakers of the minority in-group language. ${ }^{3}$ Prior to our work, evidence for such generalizations was scant. In fact, factors other than age and level of bilingualism have been downplayed in accounting for change in bilingual contexts, especially where the entire population is at an advanced stage of language shift (King 1989:145).

Still, some previous research supporting the role of social class and gender in changes taking place in bilingual contexts is available. In a study of Spanish spoken by Colombians in NYC, Orozco (2007) found that an ongoing change in the expression of futurity is being led by speakers with a high socioeconomic status. In addition, Orozco $(2007,2009$ a, 2009b) found that women are ahead of men in this ongoing change and that they are also leading the way in the increasing use of a periphrastic construction to express possession. Another example of a female-led change in Spanish in a bilingual setting comes from Alfaraz's (2010) study in Lansing, Michigan, where young women lead a change involving the increasing use of copula estar in contexts where the ser copula is expected. There is also evidence that women lead change in bilingual settings involving language pairs other than Spanish/English. In a study of Pennsylvania German spoken in Ohio, Van Ness (1995) found that young Amish women were leaders in the increased use of the neuter pronominal form es instead of the feminine form sie.

In the study that serves as foundation for the present investigation, Otheguy \& Zentella (2012) found some evidence for the impact of social class and gender on changes in pronominal use in Spanish in NYC. The authors arranged the 140 speakers in their corpus into two groups based on regional origin, Caribbean and 
Mainland Latin America. Class did not contribute to variation in pronoun rates among Caribbeans, but did distinguish between working class and middle class Mainlanders. More specifically, working class, less-educated Mainlanders used higher rates of pronouns than did middle class, more-educated Mainlanders. The authors interpret these findings as evidence that dialectal leveling accounts for the higher levels of pronoun use among working class Mainlanders. They show that blue-collar Mainlanders tend to have more contact with the high-pronoun using Caribbeans than do middle class Mainlanders, and that it is this greater contact that triggers the blue-collar Mainlander increase in pronoun use. Similarly, Otheguy \& Zentella (2012:118-24, 138-39) found that, though restricted to Mainlanders of the first generation, gender is an influential variable.

While the division of the Otheguy-Zentella corpus into two regions has revealed important observations regarding change in NYC, such a whole-sample approach leaves us with questions regarding people of various national origins. The current study more precisely pinpoints the Latinos who undergo greater and lesser amounts of change in New York. Once the people undergoing the most change are identified, we investigate whether or not social class and gender impact the move toward more Anglicized patterns of subject pronoun use in New York.

\section{E T H O D O L O G Y}

\section{Participants}

For the current study, we divide participants in the corpus into two categories intended to compare (a) speakers who have experienced little exposure to life in NYC, called NEWCOMERS, with (b) speakers with extensive experience living in NYC, whom we call NEw YoRKeRs or NYs. Our newcomers arrived in NYC at a linguistically mature age and had been in the US for only a short time when the interview was conducted; their speech thus most closely resembles that of the country of origin. Our New Yorkers, by contrast, were either born in New York or have had a large amount of exposure to NYC life. The specific criteria for operationalizing the division of consultants into newcomers and NYs in the present work are as follows. ${ }^{4}$

- NewCOMERS arrived at age seventeen or older and had not spent more than five years in NYC at the time of the interview.

- New YoRKers are all participants who are not newcomers, including speakers who (a) were born in NYC, or (b) arrived at age sixteen or younger, or (c) arrived at age seventeen or older but had spent more than five years in the City at the time of the interview.

The distribution of newcomers and NYs is presented in Table 1. 
TABLE 1. Number of consultants in Otheguy-Zentella corpus, by exposure.

\begin{tabular}{lccr}
\hline \hline National origin & Newcomers & NYs & Total \\
\hline Colombia & 6 & 15 & 21 \\
Cuba & 7 & 17 & 24 \\
Dominican Republic & 6 & 18 & 24 \\
Ecuador & 8 & 16 & 24 \\
Mexico & 6 & 17 & 23 \\
Puerto Rico & 6 & 18 & 24 \\
Total & 39 & 101 & 140 \\
\hline \hline
\end{tabular}

While there are twice as many NYs as there are newcomers, there are, in each national-origin group, similar numbers of newcomers (ranging from six to eight) and similar numbers of NYs (ranging from 15 to 18). Therefore, when we examine the extent of change between the newcomer and the NY stages, we can compare national-origin groups without concern for imbalances that would create a confounding variable.

\section{The data: Variable subject pronoun use}

The data in this study include tokens of all tensed verbs in the OtheguyZentella corpus that occur with a subject pronoun but could have occurred without one, or that are found without a pronoun but could have been found with one. In other words, we examine tensed verbs appearing in contexts where pronoun usage is VARIABLE, where both presence and absence of a pronoun is possible. To illustrate, consider (1), produced by a Cuban woman. The instance where a pronoun could have occurred but did not is indicated by the symbol $\varnothing$ in the Spanish original and by parentheses in the English translation.

(1) Yo veo varias novelas. Porque es en lo único que $\varnothing \underline{\text { me entretengo. }}$

'I see various soap operas. Because that's the only way (I) entertain myself.'

Notice that in the first underlined verb the speaker produces a pronoun yo that she could have easily omitted. In the following sentence with the verb me entretengo, she does not insert yo, but could have done so. Not all contexts are considered variable. Contexts where the pronoun is mostly always present or mostly always absent are not included in this study. For example, the use of subject pronouns referring to inanimates is so infrequent that it makes sense to restrict the analysis to verbs whose subjects make animate references. For an in-depth discussion of inclusions and exclusions, see Otheguy \& Zentella (2012:45-67). 


\section{R E S U L T S}

For all analyses in the current study, the dependent variable is the pronoun rate. A speaker's pronoun rate is the percentage of verb tokens that occur with a pronoun out of all verb tokens. For example, participant 194C, a twenty-four-year-old woman from Barranquilla, Colombia, produced 375 tensed verbs. Of these, seventy-one occurred with a subject pronoun, so this participant's pronoun rate is nineteen percent.

In order to provide the necessary context, we begin with tables that restate some of the known findings regarding the increased use of pronouns in Spanish in NYC, followed by the new findings regarding national-origin groups. We then present the external factors impacting the use of pronouns in the group undergoing the most change, and, finally, show that none of these social factors have any influence on the group undergoing the least change.

\section{Exposure and pronoun rates in NYC}

An initial simple comparison shows that NYs have higher pronoun rates than newcomers (see Table 2).

TABLE 2. Pronoun rate by exposure (newcomers vs. NYs).

\begin{tabular}{|c|c|c|c|c|c|c|}
\hline \multicolumn{3}{|c|}{ Newcomers } & \multicolumn{3}{|c|}{ NYs } & \multirow[t]{2}{*}{$\%$ Point increase } \\
\hline $\mathrm{N}$ & Pro Rate & SD & $\mathrm{N}$ & Pro Rate & SD & \\
\hline 39 & 30 & 11 & 101 & 35 & 12 & +5 \\
\hline
\end{tabular}

A one-way ANOVA performed using the pronoun rate as the dependent variable and exposure (newcomer vs. NY) as the independent variable confirms that the difference of pronoun rate shown in Table 2 is significant $[F(1,139)=5.89$, $p=.02]$ with a medium effect size $[d=.42]$.

\section{Exposure, national origin, and pronoun rates in $N Y C$}

Now that we have shown some of the familiar evidence for the change in progress in Spanish in New York, we provide new findings comparing the pronoun rate of newcomers to that of NYs separately for each national group. The change is measured in percentage-point increases in the pronoun rate (see Table 3).

The right-most column in Table 3 shows that the percentage-point increase from the newcomer to the NY stage constitutes a widespread trend, as it takes place in all national-origin groups except one. Note also that the increase is greater in some groups than in others, allowing us to rank them. 
TABLE 3. Pronoun rate by national origin and exposure (newcomers vs. NYs).

\begin{tabular}{|c|c|c|c|c|c|c|c|}
\hline \multirow{2}{*}{ National origin } & \multicolumn{3}{|c|}{ Newcomers } & \multicolumn{3}{|c|}{ NYs } & \multirow{2}{*}{$\%$ Point increase } \\
\hline & $\mathrm{N}$ & Pro Rate & SD & $\mathrm{N}$ & Pro Rate & SD & \\
\hline Colombia $^{a}$ & 6 & 25 & 11 & 15 & 36 & 7 & +11 \\
\hline $\mathrm{Cuba}^{\mathrm{b}}$ & 7 & 33 & 7 & 17 & 40 & 11 & +7 \\
\hline Puerto Rico & 6 & 35 & 4 & 18 & 40 & 7 & +5 \\
\hline Mexico & 6 & 19 & 7 & 17 & 23 & 8 & +4 \\
\hline Ecuador & 8 & 27 & 10 & 16 & 29 & 9 & +2 \\
\hline Dominican Republic & 6 & 42 & 10 & 18 & 41 & 14 & -1 \\
\hline
\end{tabular}

${ }^{\mathrm{a}}=p<.05 ;{ }^{\mathrm{b}} p=<.10$

We now compare each of the national groups by means of six ANOVAs (one for each line of Table 3). ANOVAs measure whether the variance ACROSs the groups (in this case, across newcomers and NYs) is greater than the differences WITHIN the groups (in this case, differences within each national-origin newcomer group and differences within each national-origin NY group). The results for each national-origin group show that the between-group to within-group ratio, which is captured by the $F$ statistic, follows the same national ranking that is obtained by comparing percentage point changes. Colombians show the most difference between newcomers and NYs $(F(1,20)=7.52, p=.01)$, followed by Cubans $(F(1,23)=3.10, p=.09)$, Puerto Ricans $(F(1,23)=2.94, p=.10)$, Mexicans $(F$ $(1,22)=1.18, p=.29)$, Ecuadorians $(F(1,21)=.26, p=.61)$, and, finally, Dominicans $(F(1,23)=.01, p=.91)$. The ANOVA results show that Colombians and Cubans are not only the groups that change the most, but are also the two groups where the change reaches the clearest level of statistical significance.

The main inference we draw from these national-origin comparisons is that $\mathrm{Co}$ lombians and Cubans are the groups who undergo the most substantial change in pronoun rates in the New York City population. We include Cubans in this category despite the fact that the level of confidence for the difference of pronoun rates between newcomers and NYs in this national group is $p=.09$. Heeding advice from statisticians (Newton \& Rudestam 1999:65), we do not always reject results with $p$ values above .05. In order to avoid Type II errors whereby the researcher erroneously rejects a relevant finding, we consider the possibility that, in our New York sample, a $p$ value of between .05 and .10 can reflect a true relationship between variables holding in the New York population. To further study this relationship, we examined effect sizes for Colombians and Cubans. While the effect size for Colombians $(d=1.57)$ was larger than for Cubans, the effect size for Cubans $(d=.64)$, which is at a medium level (Cohen 1988), can serve to buttress our conclusion that Cubans in the NYC population are undergoing increases in pronoun-rate usage that are analogous to those of Colombians. ${ }^{6}$ 
From here on in we group Colombians and Cubans together. ${ }^{7}$ To reflect the fact that they are the speakers who undergo the most change, we refer to them as the INNOVATORS. On the opposite end of the spectrum from the innovators, we find the Dominicans, who are the only national-origin group that departs from the pattern of percentage-point increases in pronoun rate shown in Table 3; the Dominicans actually show a small pronoun-rate decrease. The results of the ANOVA support the percentage point finding. For Dominicans, the ratio of variancebetween to variance-within the two exposure groups is almost the same $(F=.01)$, and there is no significant difference between newcomer Dominicans and NY Dominicans $(p=.91)$. Thus, our results point to a case of Dominican exceptionalism. We return to this finding in the Discussion section, where we suggest that affluence impacts the extent to which communities undergo contact-induced language change.

\section{Exploring the impact of social class and gender on pronoun} rates: Innovative speakers

We now ask whether social class and gender affect changing pronoun rates among our innovators, that is, the speakers undergoing the most change. After studying the innovators in this section, in the following we raise the same question for the speakers undergoing no change, whom we call the CONSERVATIVES. Our purpose, then, is to investigate the impact of social class and gender on pronoun usage in the group that is changing the most, as well as in the group that is changing the least. We use multivariate linear regression, which measures the unique contribution of each independent predictor variable while taking into account the other predictor variables. We designate all variables used in the statistical analyses with a one- or two-word label, capitalized. The dependent variable in all of the analyses is the Pronoun Rate.

In addition to our two main predictor variables, Social Class and Gender, we include in the regression Exposure, English, and Education. We include Exposure and English to investigate whether the evidence for change in pronoun rates found in the bivariate analyses in Table 3 above is confirmed by multivariate analyses. We include Education, as it can provide information on social class. As discussed in Orozco (2009a), for immigrants in the US, education might be more reliable than socioeconomic status as an indicator of social class due to many immigrants' experience of downward mobility. All predictors are thus as listed below in (2).

(2) Predictor variables
a. EXPOSURE. Newcomers versus NYs.
b. ENGLISH. Participants whose self-reported English skills are either poor/pas- sable versus good/excellent.
c. Gender. Males versus female participants.
d. Social Class. Middle class versus working class. ${ }^{8}$
e. Education. High school education or less versus college education or more. 
In addition to analyzing each independent variable for the innovators as a whole group, we also analyze each variable for newcomer innovators and NY innovators separately.

In the tables that follow, we provide $\mathrm{R}^{2}$ information, which gives the percentage of total variance accounted for by all of the variables in the regression taken together. And we provide a ranking of variables according to their predictive power of occurrence of the dependent variable (in this case of the appearance of a subject personal pronoun), expressed in terms of standardized betas.

Several different regressions must be performed to avoid the problem of collinearity, which arises when predictor variables are conceptually linked and statistically correlated (Newton \& Rudestam 1999:264). Tables 4a-d present the results.

TABLE 4A. Regression, Innovators. Dependent variable: Pronoun Rate.

\begin{tabular}{lccc}
\hline \hline $\mathrm{R}^{2}=.30^{* *}$ & N speakers & Standardized Beta & $p$ \\
\hline Exposure & 45 & $* * .50$ & .001 \\
Gender & 45 & $* .31$ & .03 \\
Social class & 40 & .01 & .92 \\
\hline \hline
\end{tabular}

$*=p<.05, * *=p<.01$

TABLE 4B. Regression, Innovators. Dependent variable: Pronoun Rate.

\begin{tabular}{lccc}
\hline \hline $\mathrm{R}^{2}=.29 * *$ & $\mathrm{~N}$ speakers & Standardized Beta & $p$ \\
\hline Exposure & 45 & $* * .47$ & .001 \\
Gender & 45 & $* .31$ & .03 \\
Education & 44 & .17 & .21 \\
\hline \hline
\end{tabular}

TABLE 4C. Regression, Innovators. Dependent variable: Pronoun Rate.

\begin{tabular}{lccc}
\hline \hline $\mathrm{R}^{2}=.21 *$ & $\mathrm{~N}$ speakers & Standardized Beta & $p$ \\
\hline English & 45 & $* .41$ & .02 \\
Gender & 45 & $* .35$ & .03 \\
Social Class & 40 & .08 & .62 \\
\hline \hline
\end{tabular}

TABLE 4D. Regression, Innovators. Dependent variable: Pronoun Rate.

\begin{tabular}{lccc}
\hline \hline $\mathrm{R}^{2}=.20^{*}$ & $\mathrm{~N}$ speakers & Standardized Beta & $p$ \\
\hline English & 45 & $* .36$ & .02 \\
Gender & 45 & $* .33$ & .03 \\
Education & 44 & .03 & .84 \\
\hline \hline
\end{tabular}


Tables $4 \mathrm{a}-\mathrm{d}$ are revealing both where they show an association between social variables and pronoun rates and where they do not. The variables that most strongly influence pronoun rates are, first and foremost, those associated with language contact, that is, Exposure and English. These analyses underscore the observation that the innovators in New York are in the midst of a change in progress, and that this change is associated with language contact. In addition, we see significant effects for Gender. By contrast, the results show neither Social Class nor Education as significant predictors of pronoun rates.

The significant impact of gender revealed in the multivariate analyses warrants further investigation so as to pinpoint the women effect in NYC. Otheguy \& Zentella (2012:119) found significant gender effects among Mainlander NYs who arrived after their third birthday. Following their lead, we performed an ANOVA with Pronoun Rate as the dependent variable and Gender as the independent variable, but this time we excluded the NYs who arrived in the US by their third birthday. For this subsample of twenty-three NYs whom we call "established immigrants," there was a clear pattern. Female established-immigrant innovators produced higher rates of pronouns (forty-one percent) than their male counterparts (thirty-one percent), and this difference was significant by $\operatorname{ANOVA}(F(1,22)=$ $5.78, p=.03)$. Thus, the combined results from the multivariate and bivariate analyses point to a clear women effect in the ongoing change in NYC, and the bivariate analyses tell us that the effect is found especially among speakers who were born in Latin America but have had extensive exposure to NYC.

We learn from these results that what is conditioning the increasing use of pronouns among innovators, in addition to the passage of time in New York and across the generations, is whether the consultant has a strong command of English, and whether the consultant is a man or a woman. We learn further that the social class or the level of education of the individual speaker does not matter for this ongoing change.

\section{Exploring the impact of social class and gender on pronoun rates: Conservative speakers}

In this section we examine, for the conservative speakers, the same social variables that we examined for the innovative speakers. The results show that social variables have no influence at all on the pronoun rates of conservative speakers. As before, we take care to avoid problems of collinearity by excluding variables that overlap.

TABLE 5A. Regression, conservative speakers $(N=24)$. Dependent variable: Pronoun Rate.

\begin{tabular}{lcr}
\hline \hline $\mathrm{R}^{2}=.16^{\mathrm{ns}}$ & Standardized Beta & $p$ \\
\hline Gender & -.25 & .30 \\
Social Class & .24 & .33 \\
Exposure & .07 & .76 \\
\hline \hline
\end{tabular}

ns = nonsignficant 
TABLE 5B. Regression, conservative speakers $(N=24)$. Dependent variable: Pronoun Rate.

\begin{tabular}{lcc}
\hline \hline $\mathrm{R}^{2}=.18^{\mathrm{ns}}$ & Standardized Beta & $p$ \\
\hline Gender & -.33 & .13 \\
Education & .25 & .23 \\
Exposure & .02 & .91 \\
\hline \hline
\end{tabular}

TABLE 5C. Regression, conservative speakers $(N=24)$. Dependent variable: Pronoun Rate.

\begin{tabular}{lcc}
\hline \hline $\mathrm{R}^{2}=.18^{\mathrm{ns}}$ & Standardized Beta & $p$ \\
\hline Social Class & .44 & .26 \\
English & -.28 & .47 \\
Gender & -.28 & .22 \\
\hline \hline
\end{tabular}

TABLE 5D. Regression, conservative speakers $(N=24)$. Dependent variable: Pronoun Rate.

\begin{tabular}{lcc}
\hline \hline $\mathrm{R}^{2}=.18^{\mathrm{ns}}$ & Standardized Beta & $p$ \\
\hline Gender & -.33 & .14 \\
Education & .27 & .25 \\
English & .03 & .89 \\
\hline \hline
\end{tabular}

As expected from the percentage-point and ANOVA results of Table 3, the results from Tables 5a-d confirm that neither exposure to NYC (Tables 5a and 5b) nor English proficiency (Tables $5 \mathrm{c}$ and $5 \mathrm{~d}$ ) is a significant predictor of the conservative speakers' pronoun rates. That is, the two variables associated with contact are not operative in this community, underscoring the finding that the variable use of pronouns among Dominicans in New York is not undergoing change. In addition, no other external variable is operative among these conservative speakers, indicating that pronoun use in such a situation of stable variation is impervious to the impact of social variables.

\section{Summary of results}

We have isolated a set of external variables that are newly discovered to play a role in a contact-induced change in progress having to do with the variable use of subject pronouns in Spanish in New York City. Going beyond the variables related to regional origin, immigrant generation, and exposure to the New York environment that had been discovered in previous research, we have shown the relevance of variables having to do with differences between national-origin groups and between men and women. An important finding here is that national-origin groups in 
NYC differ when it comes to susceptibility to English influences in the use of Spanish pronouns. Building on our discovery regarding the national-origin groups that seem to be changing most and least, we have learned that conditioning variables tend to influence the variable use of pronouns in the group that is changing but not in the group that is stable. The contrast, then, between the innovative and conservative speakers is quite clear. The innovators are a changing group (Exposure and English are significant), and are differentiated internally by the gender of the consultants. The conservatives are a much more stable group (Exposure and English are not significant), and show no internal differentiation with respect to social variables. We now raise the question of why the innovating group is more susceptible to English influences than the conservative one and why it is that the groups differ with respect to the influencing factors that affect their variability.

D I S C U S I O N O F N A T I O N A - O R I G I N G O U P A N C C A NGE IN PRONOUN USE

The finding that some national-origin groups in NYC undergo more change than others in their use of subject personal pronouns is presented in graphic form in Figure 1 . The $\gg$ symbol, distinguished from the $>$ symbol, is to remind the reader that Dominicans are the only speakers in our sample of Latino New Yorkers who undergo no increase in pronoun rates.

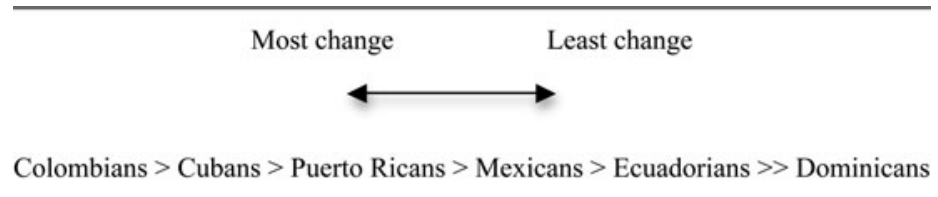

FIGURE 1. Ranking of change in pronoun rates among six national-origin groups in NYC.

In an attempt to gain more purchase on the reasons why some groups change more than others, we looked for other factors that distinguish between them, and found that the pronoun-rate ranking of the groups closely mirrors national, as well as city-wide, socioeconomic ranking of Latinos. The innovators in NYC tend to be the most affluent Latinos in the US and, more specifically, in NYC. In contrast, the conservatives tend to be the poorest. Figure 2 below illustrates this parallel. For ease of presentation, Figure 2a repeats the differential impact of exposure on the six national-origin groups presented in Figure 1. Figure $2 b$ illustrates the Pew Hispanic Center's (2009) affluence rankings for Latinos in the US as a whole (Dockterman 2011), and Figure 2c illustrates the rankings of NYC (adapted from Treschan 2010, Treschan, p.c. 2012). 


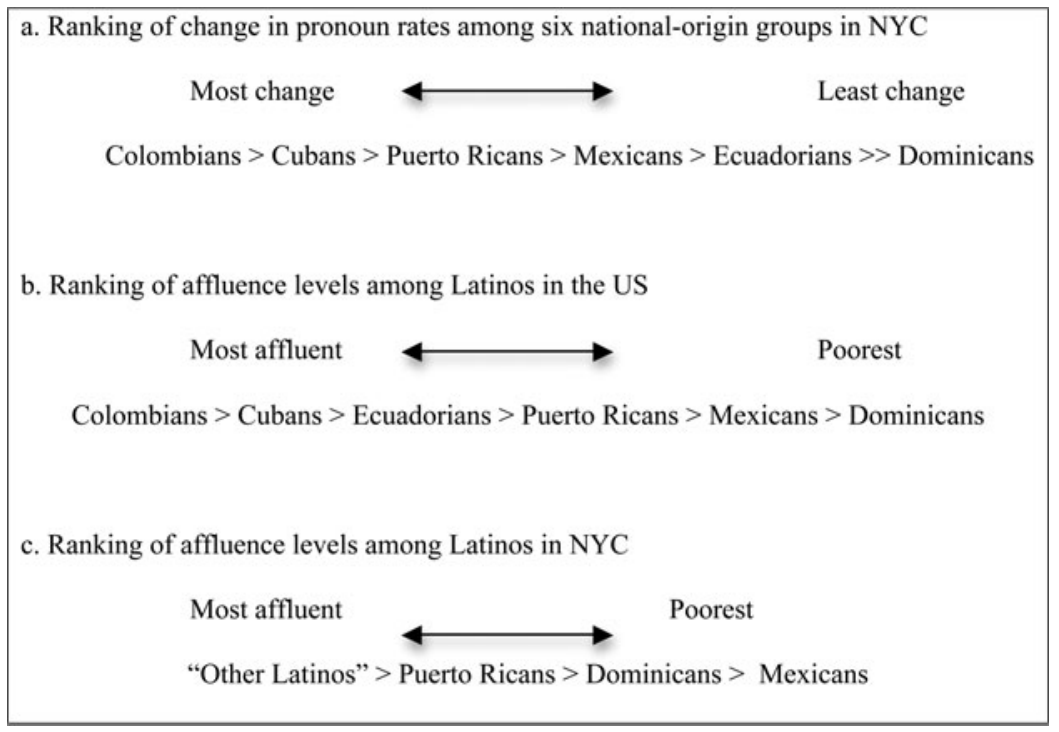

FIGURE 2. Comparison of pronoun rate change and affluence rankings.

The figures show a small difference between US and NYC rankings that does not, however, affect our point. Mexicans are poorer than Dominicans in NYC, whereas Dominicans are poorer than Mexicans when the entire US is taken into consideration. The point remains that Mexicans and Dominicans are the poorest of all Latinos, and that they are the two groups that undergo little or no change in pronoun rates in New York. The figures support our contention that affluence rankings can provide an external explanation for the national-origin differences in the increases in pronoun rate that we have documented in Table 3. Our results are further buttressed by Orozco's (2007) research on Spanish spoken by Colombians in NYC, in which Colombians of higher socioeconomic status are leading an ongoing change in the expression of futurity.

Why do affluent Latinos in NYC tend to be innovators and why do less affluent ones tend to be conservative in this use of subject pronouns? We propose an explanation that draws from the literature on social networks. People of lower socioeconomic status tend to have denser social networks, which results in greater retention of minority languages (Hudson, Hernández Chávez, \& Bills 1995; Bills, Hudson, \& Hernández Chávez 2000) and, more to our point, more conservative language usage patterns (Milroy 1987; Milroy \& Milroy 1992). In addition to having denser social networks, poorer Hispanic communities are likelier to have a larger representation of recent immigrants from Latin America. Data from the 2010 US Census for the NYC metropolitan area show that the Dominican community is comprised of more recent immigrants and is, on the whole, more Spanish-speaking than 
the Colombian and Cuban communities. In communities with many recent newcomers, the usage of the community as a whole will resemble that of its newcomers more than in communities that are on average longer-settled in the City. This community-wide resemblance to the community's newcomers is, in part, what we are detecting in the conservative use of pronouns that we have documented for our New York Dominicans. Moreover, in communities that are more Spanish-speaking, it is likely that there is less English being used, accounting for its lesser influence among the Dominicans in our sample.

In contrast to the poorest Hispanic communities, Latinos who are on average more affluent (i.e. our innovating Colombians and Cubans) are likely to have looser social networks and, therefore, to be more susceptible to external influence and change. In addition, affluence tends to be correlated with more interaction with the dominant Anglophone communities, thereby decreasing connection to the Spanish-speaking communities and very likely increasing bilingualism, resulting in greater susceptibility to change in Spanish usage patterns.

While we have established that the overall affluence of one's community is associated with linguistic change in the bilingual setting, the social class status of individual speakers appears to be less relevant. Our analyses show no relationship between an individual's self-reported social class status and his or her pronoun use (not among the changing Colombians and Cubans, nor among the stable Dominicans). Thus, the overall socioeconomic make-up of a community and the strength of its social network influence the degree to which community members' speech undergoes change, but each individual's place within the community is less relevant.

The connection between affluent communities and language change might also account for some discrepancies in the literature regarding change in Spanish pronoun use in the US. While studies on Spanish in New York City show strong evidence of change in pronoun use, studies of Spanish in other parts of the US have not found as clear a pattern (Travis 2007; Torres Cacoullos \& Travis 2011). Perhaps the greater change in NYC can be attributed to the weaker social networks of a large, impersonal metropolis, while the denser social networks and greater maintenance of Latin American patterns of pronominal use may be due to the less alienating environments that are perhaps found in smaller settings.

Our explanation for the apparent lack of change in pronoun use among Dominicans is bolstered by other research showing that Dominicans in the US tend to be more conservative in their use of language than other Hispanics. In her work, Toribio (2000a, 2000b:261) characterizes Dominicans as "extremely language-retentive, maintaining and advancing the Dominican Spanish dialect" and resisting influence from other varieties of Spanish. ${ }^{10}$ Indeed, studies based on census data show that Dominicans in the US maintain Spanish language use more persistently and longer than other Hispanic groups, as well as other immigrant groups in general (Alba, Logan, Lutz, \& Stults 2002; Johnson, Ríos, Drewery, Ennis, \& Kim 2010:2). This trend appears to continue, as the 2010 census data show that ninety-five percent of Dominicans in NYC speak Spanish. 
Why are Dominicans so exceptional in resisting language change, as proposed by Toribio and demonstrated here with regard to pronouns? Above we offered one explanation that connected poverty with greater resistance to change. Another explanation is offered by Toribio (2000a, 2000b), who interprets the Dominican tendency towards linguistic and dialectal maintenance as a mechanism for expressing community unity and separation from non-Dominican groups, most notably from African-Americans. As there are many more nonwhites among Dominicans than among other Latino communities, they encounter racism in the US in a virulent form. This experience becomes particularly jarring in light of their own perception of difference from the US African-American community. Thus, Toribio (2000b:263ff) argues that maintaining Spanish and Hispanic identity is one way that Dominicans disassociate from AfricanAmericans and, more generally, avoid being perceived as members of a disadvantaged minority.

In addition to the external factors that result in a lack of change among Dominicans, we think that there is also an internal factor at work. We propose that the Spanish grammar has an internal ceiling that disallows pronoun use past a certain occurrence rate. Our speculation is grounded in a functional view of pronoun usage, a view that interprets the presence or absence of pronouns as a mechanism of providing information about whether or not a referent is easy to find. The more accessible a referent is, the more likely it is that the speaker will omit a pronoun instead of including it (Chafe 1976; Givón 1983; Ariel 1990; Gundel, Hedberg, \& Zacharaski 1993). The ceiling effect operates to maintain the reference-tracking mechanism embodied in pronouns, which is likely to become inoperative when pronoun use starts to approach a rate of fifty percent.

Evidence for the ceiling effect comes from the breadth of research on Spanish subject pronoun use. Rarely in the Spanish-speaking world do we find average pronoun rates above forty-five percent. The Dominicans in our study arrive in the City with an average pronoun rate of forty-two percent, which is the highest rate documented in the Otheguy-Zentella corpus, including both newcomers and NYs (see Table 3). Other scholars have confirmed that Dominicans are the highest pronoun users in the Spanish-speaking world (Ortiz López 2011). If, starting from such a high base, Dominicans were to undergo significant increases in pronoun rates in NYC, they would be pushing against what we conjecture is the internal restriction on maximum pronoun use. It may well be the case that Dominican Spanish is heading toward a dramatic structural reorganization, as this variety registers types of usages rarely or never attested in other varieties (Jiménez Sabater 1977:13-14, Toribio 2000c). But for now, alternation is still current among Dominicans, restricted in the manner just described. This is the restriction, then, that provides another part of the explanation of why Dominicans in NYC appear to be the exception to the otherwise community-wide increase in pronoun rates. 


\section{DISCUSS I ON OF GENDER A N D L A G U A GE CHANGE IN A B ILINGUAL S ET T ING}

Among the speakers undergoing change in pronoun rates, we have found that women are ahead of their male counterparts. More specifically, this women effect appears to be strongest among established immigrants, that is, immigrants who had spent more than five years in NYC at the time they were interviewed. We consider three possible explanations. Compared to immigrant men, women might have (i) higher levels of English, (ii) more contact with varieties of Spanish other than their own, or (iii) more extensive contact with US-born bilinguals. We consider each explanation in turn and conclude that the third explanation accounts best for the women effect.

First let us consider the English contact explanation. As the change in pronoun use is, in part, due to English influence, we must consider the possibility that immigrant women experience more contact with English than do immigrant men. While this idea might seem counterintuitive, there is some evidence that the related phenomenon of shift from Spanish to English in the US is led by women (Solé 1978). Nevertheless, among the speakers undergoing change in the Otheguy-Zentella corpus, established immigrant men and women do not differ significantly with respect to English proficiency levels $\left(X^{2}(1)=.02, p=.90\right)$. We thus rule out the possibility that the women effect is simply due to higher levels of English proficiency among the women.

The second explanation we must consider for the women effect is that the immigrant women experience more extensive dialect leveling than their male counterparts do. Recall that pronoun rates tend to be higher in the Caribbean than in the Latin American Mainland. In New York City there are more Hispanics of Caribbean origin than of Mainland origin, making the high-pronoun using Caribbean variety the dominant one. Indeed, Otheguy \& Zentella (2012:99-102,11722,135-45) find evidence that Caribbeans exert an influence on Mainlanders that is greater than that of Mainlanders on Caribbeans. Could the Caribbean influence on Mainlanders account for the women effect? Such a dialect-leveling account would make sense if it could it be shown that contact between Mainlanders and Caribbeans is gender specific, that is, if Mainlander women have more contact with Caribbean speakers than Mainlander men do. If this were the case, this MainlanderCaribbean Women contact could explain the female lead in rising pronoun rates among Mainlander immigrants in particular. ${ }^{11}$ But such an account cannot entirely explain the findings in this study, since evidence for the women effect is found not only among Mainlanders, but also among Caribbeans; our innovators included are not only Colombians, but also Cubans. As Cuban newcomers arrive in NYC with a relatively high pronoun rate (thirty-three percent, as shown in Table 3) - a rate that is very similar to that of Puerto Rican newcomers, and is only surpassed by that of Dominican newcomers - it seems unlikely that contact with other varieties of Spanish is a trigger for the notable increase in pronoun rates among Cuban NYs. In other words, since dialect leveling does not adequately account for the 
Cubans' increase in pronoun rates in NYC, it cannot explain why Cuban immigrant women in particular experience a greater increase than Cuban men. ${ }^{12}$ Therefore, in order to explain the women effect, we consider yet another explanation beyond the impacts of English and dialect leveling.

We suggest that, in addition to the role of English and, in the case of Mainlanders, that of Caribbean influence, Latino immigrants are exposed to yet another high-pronoun form of Spanish, namely that of US-born Latino bilinguals. Seen this way, the women effect suggests that changes in immigrant women's Spanish are, in part, due to contact with US-born friends and family members, including their own children. This type of contact can be characterized as intergenerational contact, as it is contact between the immigrant generation and the US-born generation. Figure 3 below illustrates the change in progress, as well as the sources for the change experienced by both immigrant and US-born Latinos, highlighting the women effect in the top arrow. We leave aside dialectal leveling as the graphic attempts to capture change in both Mainlander and Caribbean immigrants.

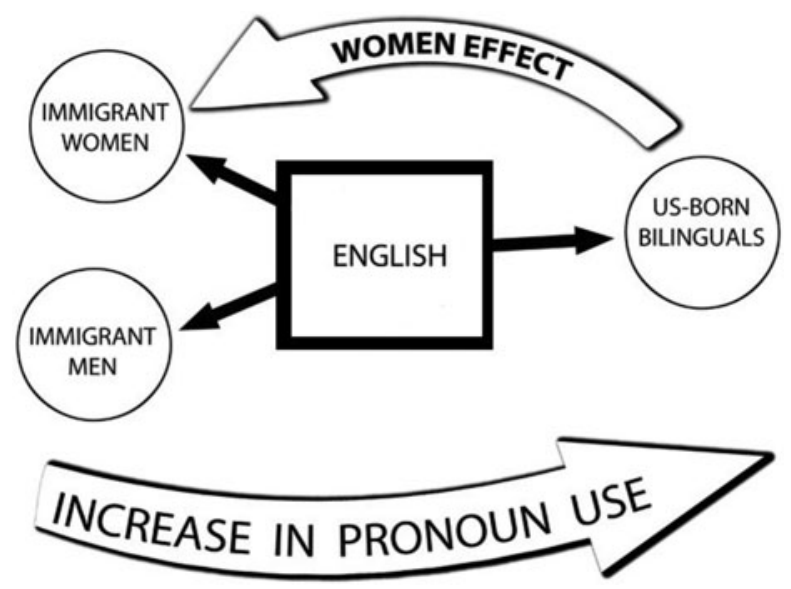

FIGURE 3. Sources of change in pronoun rates in Spanish in NYC.

As shown in Figure 3, the proposal is that there are several sources for the change, including English and intergenerational contact. Still, the proposal highlights the interactions between members of different generations as the source of the women effect specifically, as neither English influence nor dialect leveling would sufficiently explain it. The intergenerational contact explanation also accounts for Van Ness's (1995:77) finding that older, monolingual German-speaking Amish women in Ohio employ innovative features, not because of their own contact with English, but because of extensive contact with their bilingual daughters. The women effect in bilingual settings in NYC and Ohio suggests a more general 
pattern captured by the top arrow in Figure 3, whereby changes arising among bilinguals can be transmitted in a backwards trajectory to immigrant or monolingual female relatives.

This account raises the question whether immigrant women actually interact more with US-born bilinguals, or whether it is simply the case that they are more susceptible to direct external influences. A conclusive answer to this question is beyond the scope of the current article, but we suggest that both accounts are possible. First, it is likely that women have more contact than men with US-born friends and family members, primarily due to their role as mothers of US-born bilingual children. Research on US Latinos whose parents speak different varieties of Spanish has shown that children tend to speak the dialect of their mothers, not their fathers (Potowski 2008; Potowski \& Matts 2008). This mother-to-child dialect transmission is a strong indicator that US-born Latinos have more conversations in Spanish with their mothers than with their fathers. Second, there is reason to believe that women tend to adapt and change their use of language more readily. There is research that suggests that women more than men use language to establish interpersonal sensitivity (Leaper \& Friedman 2007; Hall \& Mast 2008; Leaper \& Robnett 2011), a tendency that might well translate into an increased susceptibility to change. Furthermore, there is evidence that women more than men use language to demarcate social differences among themselves (Eckert \& McConnell-Ginet 2003:302), indicating that women have a heightened sensitivity to linguistic form and a tendency to change their own speech. We suspect that both considerations -women having more contact with US-born bilinguals and being more susceptible to change - may play a role in explaining the women effect in bilingual settings.

In light of our findings regarding a women effect in bilingual settings, following on those by Orozco $(2007,2009 b)$ and Alfaraz (2010), we propose that existing explanations for the role of women in language change need to be expanded. Both Labov (2001) and Eckert \& McConnell-Ginet (2003) explain women's innovative use of language in monolingual settings as a way of indexing nonconformity. But projecting a nonconformist social identity is not a likely explanation in bilingual settings, where language contact itself is a primary source of change. To gain a better understanding of why women are so important in advancing language change in вотн monolingual and bilingual settings, future research should examine women's roles in various social networks, as well as the possibility that women are more susceptible than men to external influences on speech patterns.

\section{S UMMARY AND CONCLUSION}

Building on previous findings regarding language contact as a shaper of the increased use of Spanish subject personal pronouns in New York City, the current study presents new findings that specific immigrant national origin, socioeconomic status, and gender are important variables for understanding this ongoing change. By examining changes in the use of pronouns among six 
different Latino national-origin groups, we have discovered that not all groups change in the same way. And we have discovered a strong link between affluence and susceptibility to change. The most affluent Hispanic communities in NYC (Colombians and Cubans) are also those who undergo the most change, while the poorest (Mexicans and Dominicans) undergo the least or no change. Our explanation for these patterns relies on the well-documented relationship between poverty and density of social networks, which results in greater resistance to linguistic change.

Expanding existing findings regarding differences between men and women in New York, we have found evidence that immigrant women are ahead of immigrant men in the ongoing change in pronominal usage in Spanish in NYC. We suggest that this women effect is due to extensive contact between US-born bilinguals and immigrant women. In other words, we incorporate the already established fact that Latin American immigrants in NYC experience significant increases in pronoun usage as a result of increasing knowledge of English (and, among Mainlanders, contact with Caribbean speakers), and add the proposition that this change is also the result of contact with US-born Hispanics whose Spanish tends toward very high rates of pronominal use. And we propose that immigrant women change more than immigrant men because they have more contact with US-born Latino friends and family members, including their children, and because women's speech patterns are, in general, more susceptible to external influences.

We have learned from our study of an ongoing change in Spanish in New York that external factors play an important role in linguistic change not only in monolingual settings, but also in bilingual ones. In the past, generalizations regarding external factors on the trajectory of linguistic change have been based entirely on change among monolinguals. But since bilingual contexts are the worldwide norm (de Groot \& Kroll 1997:1-2; Li Wei 2000:5), these statistically more prevalent settings need to be considered when proposing broad generalizations about language change. It appears now that, with respect to social class, patterns of change in bilingual communities diverge from those in monolingual ones. Whereas linguistic change in monolingual settings is often initiated and spread by working class people, our study shows that in the bilingual setting more affluent communities undergo the most change. By contrast, with respect to gender, we see a similar pattern in monolingual and bilingual settings, as women are at the vanguard of change in both. Thus the existing explanations of the women effect, which have focused on the relationship between language change and the projection of social nonconformity (Labov 2001; Eckert \& McConnell-Ginet 2003), need to incorporate the finding here. We suggest that women's roles in various social networks, as well as women's heightened sensitivity to interlocutors, may increase their linguistic susceptibility to external influences. 


\section{SOCIAL CLASS AND GENDER IMPACTING CHANGE}

\section{N O T E S}

*The authors wish to thank Helen Cairns, Ana Celia Zentella, as well as the two reviewers and the journal editor, for their helpful feedback on the manuscript.

${ }^{1}$ Scholars have cautioned against relying on occurrence rates to demonstrate differences between groups of speakers (Travis 2007; Poplack \& Levey 2010; Torres Cacoullos \& Travis 2010, 2011). Nevertheless, the contact effect in Spanish in NYC has been shown not only in increases in the overall pronoun rate, but also in changes in the ranges of the grammatical constraints that guide the use of pronouns, indicating that pronoun rates should not necessarily be disregarded (Otheguy \& Zentella 2012:216-17).

${ }^{2}$ In sociolinguistics, it is common to use differences between generations (known as "apparent time" differences) as evidence for diachronic change (Bailey 2004).

${ }^{3}$ Studies of language shift and its leaders are numerous (Gal 1979; Li Wei 1994; Holmes 1996; Bills et al. 2000; Ihemere 2011).

${ }^{4}$ The exposure variable in Otheguy \& Zentella (2012:33-34) consists of three categories (newcomers, established immigrants, and New York raised); ours consists of two categories (newcomers and NYs). Thus our NY category includes Otheguy \& Zentella's established immigrants and New York raised.

${ }^{5}$ The number at the end of all examples is that of the participant. This participant had been in the United States for three years at the time of the interview.

${ }^{6}$ Our approach raises the question of why we should include Colombians and Cubans in our innovating group but exclude Puerto Ricans. Colombians and Cubans are (a) the two highest changers in terms of pronoun rate increase; (b) the only two groups that show increases of more than five percentage points; and (c) the only two groups whose $F$ coefficients are greater than 3.00. There is also the purely practical consideration that our sample, which is balanced for gender for each nationality, is not balanced for gender for nationality and for exposure status. That is, we have Puerto Rican women in our sample, but no Puerto Rican newcomer women, which makes it impossible for us to discuss gender effects among Puerto Rican newcomers.

${ }^{7}$ There are strong reasons supporting our decision to combine Colombians and Cubans into the innovator group, despite the fact of group internal variation (which is, in any case, also found in groups consisting of only one nationality). First, our innovating Colombians and Cubans are the two national groups that undergo the most change, as shown in Table 3. Second, Otheguy \& Zentella (2012:73) find that Colombians differ significantly from Dominicans, but not from Cubans or Puerto Ricans. Third, there is nothing sacrosanct about national origin as a tool for identifying dialectal groupings. For example, there appears to be wide variation within Colombia, and scholars have argued that the Spanish spoken on the Colombian coast shares many features with that of Cuba, Puerto Rico, and the Dominican Republic (Lipski 1994:6; Orozco \& Guy 2008; but also see Claes 2011).

${ }^{8}$ An anonymous reviewer suggested that social class should include more than two categories. But among the innovators, only one participant said he was upper class. Therefore we only include two categories (working and middle class).

${ }^{9}$ Some speakers are excluded from the analyses due to missing data for Social Class $(\mathrm{N}=5)$ or for Education $(\mathrm{N}=1)$.

${ }^{10}$ In her study of lexical items in Spanish in New York, Zentella (1990) found that Dominicans more readily adopt Spanish words employed by other national-origin groups, while Colombians, Cubans, and Puerto Ricans reject words associated with the Dominican variety. Thus, Dominicans change their lexicon more than other groups, which Zentella (1990:1102) attributes to the stigmatization associated with Dominican Spanish. But speakers are often highly aware of lexical variation making lexical usage easily stigmatized. Laypeople are not as aware of morphosyntactic variation. In Avila-Jiménez's (1996:129) study, Puerto Rican consultants were surprised when they learned that there are dialectal differences associated with subject pronoun use in Spanish.

${ }^{11}$ Research on exogamous marriages presents one way to explore the question of gender-specific dialect leveling. About a third of out-group marriages recorded among Hispanics in NYC are intermarriage between Hispanic groups, as opposed to Hispanic-Anglo marriages (Gilbertson, Fitzpatrick, \& Yan 1996). In other words, it is common for Colombians to marry Puerto Ricans, Puerto Ricans to marry

Language in Society 42:4 (2013) 


\section{NAOMI LAPIDUS SHIN AND RICARDO OTHEGUY}

Dominicans, and so on. But it is unclear at this point whether or not there is a greater proportion of Mainlander-women-Caribbean-men marriages than Mainlander-men-Caribbean-women marriages.

${ }^{12} \mathrm{An}$ anonymous reviewer suggested that perhaps the ongoing change in pronoun use begins in the Caribbean and then is accelerated in the NYC contact setting, which is arguably the case for the increasing use of the periphrastic construction to express futurity (Orozco 2007; Claes \& Ortiz López 2011). If we apply this line of thinking to pronoun use in NYC, then the women effect among Cubans could perhaps be traced back to Cuba and, therefore, attributed to the common situation in monolingual settings where women lead change. Then, the women effect among Colombians could be due to extensive interaction between Colombian women and Caribbean speakers of Spanish in NYC. While this idea is worth investigating, evidence thus far does not point to a female-led change in progress in the Caribbean (AvilaJiménez 1995:36). We would also argue that, in either case — whether the change originates in NYC or in Latin America-intergenerational contact between immigrant women and their US-born children is likely to play a role in the transmission of the change.

\section{REFERENCES}

Alba, Richard; John Logan; Amy Lutz; \& Brian Stults (2002). Only English by the third generation: Loss and preservation of the mother tongue among the grandchildren of contemporary immigrants. Demography 39(3):467-84.

Alfaraz, Gabriela (2010). The influence of social factors on Spanish dialect contact in the U.S.: A look at Mexican and Cuban Spanish in a Midwestern city. Southwest Journal of Linguistics 29(2):27-54.

Ariel, Mira (1990). Accessing noun-phrase antecedents. London: Rutledge.

Avila-Jiménez, Bárbara (1995). A sociolinguistic analysis of a change in progress: Pronominal overtness in Puerto Rican Spanish. Cornell Working Papers in Linguistics 13:25-47.

(1996). Subject pronoun expression in Puerto Rican Spanish: A sociolinguistic, morphological, and discourse analysis. Ithaca, NY: Cornell University dissertation.

Bailey, Guy (2004). Real and apparent time. In J. K. Chambers, Peter Trudgill, \& Natalie Schilling-Estes (eds.), The handbook of language variation and change, 312-32. Cambridge: Blackwell.

Bills, Garland; Alan Hudson; \& Eduardo Hernández Chávez (2000). Spanish home language use and English proficiency as differential measures of language maintenance and shift. Southwest Journal of Linguistics 19(1):11-27.

Chafe, Wallace (1976). Givenness, contrastiveness, definiteness, subjects, topics, and point of view. In Charles N. Li (ed.), Subject and topic, 25-55. New York: Academic Press.

Cheshire, Jenny (2004). Sex and gender in variationist research. In J. K. Chambers, Peter Trudgill, \& Natalie Schilling-Estes (eds.), The handbook of language variation and change, 423-43. Cambridge: Blackwell.

Claes, Jeroen (2011). ¿Constituyen las Antillas y el Caribe continental una sola zona dialectal? Datos de la variable expresión del sujeto pronominal en San Juan de Puerto Rico y Barranquilla, Colombia. Spanish in Context 8(2):191-212.

Claes, Jeroenn, \& Luis Ortiz López (2011). Restricciones pragmáticas y sociales en la expresión de futuridad en el español de Puerto Rico. Spanish in Context 8(1):50-72.

Cohen, Jacob (1988). Statistical power analysis for the behavioral sciences. New York: Routledge.

de Groot, Annette, \& Judith Kroll (1997). Introduction and overview. In Annette de Groot \& Judith Kroll (eds.), Tutorials in bilingualism, 1-18. Mahwah, NJ: Lawrence Erlbaum.

Dockterman, Daniel (2011). Country of origin profiles. Pew Hispanic Center research report. Online: http://www.pewhispanic.org/2011/05/26/country-of-origin-profiles/.

Eckert, Penelope (1989). Jocks and burnouts: Social categories and identity in the high school. New York: Teachers College Press.

_ \& Sally McConnell-Ginet (2003). Language and gender. Cambridge: Cambridge University Press. 
Gal, Susan (1979). Language shift: Social determinants of linguistic change in bilingual Austria. San Francisco, CA: Academic Press.

Gilbertson, Greta; Joseph Fitzpatrick; \& Lijun Yang (1996). Hispanic intermarriage in New York City: New evidence from 1991. International Migration Review 30(2):445-59.

Givón, Talmy (1983). Topic continuity in discourse: The functional domain of switch reference. In John Haiman \& Pamela Munro (eds.), Switch reference and universal grammar, 51-81. Amsterdam: John Benjamins.

Gundel, Jeannette; Nancy Hedberg; \& Ron Zacharaski (1993). Cognitive status and the form of referring expressions in discourse. Language 69:274-307.

Hall, Judith, \& Marianne Schmid Mast (2008). Are women always more interpersonally sensitive than men? Impact of goal and content domain. Personality and Social Psychology Bulletin 34:144-55.

Holmes, Janet (1996). Sex and language. In Hans Goebl, Peter Nelde, Zdenek Stary, \& Wolfgang Wölck (eds.), Contact linguistics: An international handbook of contemporary research, 720-25. Berlin: Walter de Gruyter.

Hudson, Alan; Eduardo Hernández Chávez; \& Garland Bills (1995). The many faces of language maintenance: Spanish language claiming in five Southwestern states. In Carmen Silva-Corvalán (ed.), Spanish in four continents: Studies in language contact and bilingualism, 165-83. Washington, DC: Georgetown University Press.

Ihemere, Kelechukwu (2011). Language choice and language shift in Port Harcourt. In Kelechukwu Ihemere (ed.), Language contact and language shift: Grammatical and sociolinguistic perspectives, 140-54. Munich: LINCOM Europa.

Jiménez Sabater, Maximiliano (1977). Estructuras morfosintácticas en el español dominicano: Algunas implicaciones sociolingüísticas. Ciencia y Sociedad II:5-20.

Johnson, Tallese; Merarys Ríos; Malcolm Drewery; Sharon Ennis; \& Myoung Ouk Kim (2010). People who spoke a language other than English at home by Hispanic origin and race: 2009. US Census Bureau Report. Online: http://www.census.gov/prod/2010pubs/acsbr09-19.pdf.

King, Ruth (1989). On the social meaning of linguistic variability in language death situations: Variation in Newfoundland French. In Nancy Dorian (ed.), Investigating obsolescence: Studies in language contraction and death, 139-48. Cambridge: Cambridge University Press.

Labov, William (2001). Principles of linguistic change: Social factors. Cambridge, MA: Blackwell.

(2006). The social stratification of English in New York City. 2nd edn. Cambridge: Cambridge University Press.

Leaper, Campbell, \& Carly Friedman (2007). The socialization of gender. In Joan Grusec \& Paul Hastings (eds.), Handbook of socialization: Theory and research, 561-87. New York: Guilford.

— \& Rachael Robnett (2011). Women are more likely than men to use tentative language, aren't they? A meta-analysis testing for gender differences and moderators. Psychology of Women Quarterly 35(1):129-42.

Li Wei (1994). Three generations, two languages, one family: Language choice and language shift in a Chinese community in Britain. Clevedon: Multilingual Matters.

Li Wei (2000). Dimensions of bilingualism. In Li Wei (ed.), The bilingualism reader, 3-25. London: Routledge.

Lipski, John (1994). Latin American Spanish. London: Longman.

Livert, David, \& Ricardo Otheguy (2010). A multilevel statistical analysis of changes in language use among first-generation immigrants in a bilingual setting. International Journal of the Sociology of Language 2010(203):83-99.

Milroy, Lesley (1987). Language and social networks. 2nd edn. Oxford: Basil Blackwell.

- \& James Milroy (1992). Social network and social class: Toward an integrated sociolinguistic model. Language in Society 21:1-26.

Newton, Rae, \& Kjell Erik Rudestam (1999). Your statistical consultant: Answers to your data analysis questions. Thousand Oaks, CA: Sage. 


\section{NAOMI LAPIDUS SHIN AND RICARDO OTHEGUY}

Orozco, Rafael (2007). Social constraints on the expression of futurity in Spanish-Speaking urban communities. In Jonathan Holmquist, Augusto Lorenzino, \& Lotfi Sayahi (eds.), Selected proceedings of the Third Workshop on Spanish Sociolinguistics, 103-12. Somerville, MA: Cascadilla Proceedings Project.

- (2009a). El castellano del Caribe colombiano a comienzos del siglo XXI. Revista Internacional de Lingüística Iberoamericana 7:95-113.

(2009b). La influencia de factores sociales en la expresión del posesivo. Lingüística 22:35-60.

—_ \& Gregory Guy (2008). El uso variable de los pronombres sujetos: ¿Qué pasa en la costa Caribe colombiana? In Maurice Westmoreland \& Juan Antonio Thomas (eds.), Selected proceedings of the 4th Workshop on Spanish Sociolinguistics, 70-80. Somerville, MA: Cascadilla Proceedings Project.

Ortiz López, Luis (2011). Spanish in contact with Haitian Creole. In Manuel Díaz-Campos (ed.), The handbook of Spanish sociolinguistics, 418-45. Oxford: Blackwell.

Otheguy, Ricardo, \& Ana Celia Zentella (2012). Spanish in New York: Language contact, dialectal leveling, and structural continuity. Oxford: Oxford University Press.

—_ Ana Celia Zentella; \& David Livert (2007). Language and dialect contact in Spanish in New York: Towards the formation of a speech community. Language 83:770-802.

Poplack, Shana, \& Stephen Levey. (2010). Contact induced grammatical change: A cautionary tale. In Peter Auer \& Jürgen Erich Schmidt (eds.), Language and space: An international handbook of linguistic variation, vol. 1, 391-418. Berlin: Mouton de Gruyter.

Potowski, Kim (2008). "I was raised talking like my mom." The influence of mothers in the development of MexiRicans' phonological and lexical features. In Mercedes Niño-Murcia \& Jason Rothman (eds.), Bilingualism and identity. Spanish at the crossroads with other languages, 201-20. Philadelphia: John Benjamins.

— \& Janine Matts (2008). MexiRicans: Interethnic language and identity. Journal of Language, Identity, and Education 7:137-60.

Solé, Yolanda (1978). Sociocultural and sociopsychological factors in differential language retentiveness by sex. International Journal of the Sociology of Language 17:29-44.

Toribio, Almeida Jacqueline (2000a). Language variation and the linguistic enactment of identity among Dominicans. Linguistics: An Interdisciplinary Journal of the Language Sciences 38(5):1133-59.

(2000b). Nosotros somos dominicanos: Language and self-definition among Dominicans. In Ana Roca (ed.), Research on Spanish in the United States: Linguistic issues and challenges, 25270. Somerville, MA: Cascadilla Press.

- (2000c). Setting parametric limits on dialectal variation in Spanish. Lingua 10:315-41.

Torres Cacoullos, Rena, \& Catherine Travis (2010). Variable yo expression in New Mexico: English influence? In Susana Rivera-Mills \& Daniel Villa Crésap (eds.), Spanish of the US southwest: A language in transition, 189-210. Madrid: Iberoamericana/Vervuert.

— \& Catherine Travis (2011). Testing convergence via code-switching: Priming and the structure of variable subject expression. International Journal of Bilingualism 15(3):241-67.

Travis, Catherine (2007). Genre effects on subject expression in Spanish: Priming in narrative and conversation. Language Variation and Change 19:101-35.

Treschan, Lazar (2010). Latino youth in New York City. Policy brief for the Community Service Society of New York. Online: www.ccny.org; accessed March 1, 2012

Van Ness, Silke (1995). Ohio Amish women in the vanguard of a language change in Pennsylvania German in Ohio. American Speech 70(1):69-80.

Zentella, Ana Celia (1990). Lexical leveling in four New York City Spanish dialects: Linguistic and social factors. Hispania 73(4):1094-105.

(Received 07 June 2012; revision received 9 October 2012; accepted 27 October 2012; final revision received 10 January 2013) 